\title{
Analysis of Instrument Validity to Measure Junior High School Students' Mathematical Imagination
}

\author{
Novi Andri Nurcahyono ${ }^{1,2, *}$, Sufyani Prabawanto ${ }^{1}$, Didi Suryadi ${ }^{1}$, Teguh Wibowo ${ }^{3}$, Eka Novarina ${ }^{4}$ \\ ${ }^{1}$ Universitas Pendidikan Indonesia, Bandung, Indonesia \\ ${ }^{2}$ Universitas Muhammadiyah Sukabumi, Sukabumi, Indonesia \\ ${ }^{3}$ Universitas Muhammadiyah Purworejo, Purworejo, Indonesia \\ ${ }^{4}$ BBPPKS Bandung, Bandung, Indonesia
}

Received March 2, 2020; Revised April 22, 2020; Accepted April 29, 2020

Copyright $\odot 2020$ by authors, all rights reserved. Authors agree that this article remains permanently open access under the terms of the Creative Commons Attribution License 4.0 International License

\begin{abstract}
The purpose of this study was to determine the validity of the instrument to measure the imagination of junior high school students. As for the stages carried out include: 1) conducting a literature study to get indicators of mathematical imagination ability, 2) preparing instruments based on the indicators obtained, and 3) testing the validity and readability test of the instruments that have been prepared. The readability test was conducted by 30 junior high students, while the validity test was conducted by 6 experts consisting of 2 learning experts in junior high school, 2 learning evaluation experts, and 2 mathematics education experts. Readability test results state that of the 12 items created, 6 questions can be understood by students, while the other 6 questions cannot be understood by students. Furthermore, 6 questions that can be understood by students were tested for validity. The test results show that 3 items are declared valid without revision, 3 items are declared to need revision. There is 1 item that needs to be revised answer key. The validator also provides suggestions to sort the questions from the easiest to the most difficult questions.
\end{abstract}

Keywords Instrument Validity, Junior High School Students, Mathematical Imagination

\section{Introduction}

Research is said to be good if the research can produce conclusions that can be trusted. This is because the conclusion of a study is the answer to the problem that must be solved. The answers are obtained by collecting data for further analysis. Data collection is an important part of research. The right data will produce the right conclusion. To get good data, the instruments used in research must be tested properly and correctly to get appropriate data [1, 2, 3, $4,5]$. Tests that can be done include readability and validity test.

This article describes the process of validating an instrument of mathematical imagination ability of junior high school students. The instruments compiled and validated in the form of test instruments form the description. The instrument in this study was used to measure the mathematical imagination ability of junior high school students, especially $8^{\text {th }}$-grades. Based on these descriptions, the question that will be answered in this study is how is the validity of the instrument to measure the mathematical imagination ability of junior high school students? In this study, the tests carried out in instrument testing were limited to the readability test and the validity test stage. So the main purpose in this study, is to describe the readability test and test the validity of the mathematical imagination test instrument for junior high school students. The novelty produced in this study is a test instrument of mathematical imagination ability that has been tested for the readability of the questions and their validity by experts.

The instrument is a tool used by researchers in collecting data. This instrument is used to measure phenomena, collect and record valuation information, and in decision making $[6,7]$. In other opinion, the instrument serves to reveal facts into the data [8]. So, to get data that matches the conditions on the ground, the instrument needs to be validated correctly.

This research contributes to the development of an appropriate measurement tool so that it can determine the ability of mathematical imagination possessed by junior high school students. By conducting a validity test on mathematical imagination instruments, it is obtained suggestions to be used in constructing instruments that can measure mathematical imagination abilities. A valid 
instrument is expected to close the gap of data mismatch in the field. Data mismatch in the field can occur if the instruments arranged cannot be understood by students, students are not able to bring up mathematical imagination that causes students' mathematical imagination ability can not be measured. The process and results in this study will contribute to students' mathematical imagination literature, especially regarding instruments that can be used to bring up and measure the mathematical imagination of students.

\section{Method}

This research is a type of qualitative research with a descriptive approach. Participants in this study consisted of 30 8th grade junior high school students and 6 experts namely 2 mathematics learning experts in junior high school, 2 learning evaluation tools experts, and 2 educational science experts. Mathematics learning expert in junior high school is a teacher who has more than 10 years experience in teaching mathematics in 8th grade junior high school. Experts in learning evaluation tools are lecturers who have more than 5 years experience in teaching learning evaluation courses in universities. Whereas, what is meant by educational science experts in this study are mathematics education lecturers and instructors in learning mathematics in schools. The experts already have certificates of expertise in their respective fields. The role of experts in this research is as a validator for the instruments developed. While 30 students were participants in the readability test. The technique of selecting participants is random sampling. This is done based on the assumption that all 8th grade students have the same mental condition.

The instrument used to collect data in this study was a questionnaire. The questionnaire was used for the readability test and the validity test. The questionnaire for the legibility test contains whether clear items were given, suggestions, and improvements. The questionnaire for the validity test contains aspects assessed from the test instruments made related to aspects of construction, language, and material. The instrument was first compiled by conducting a literature study to obtain definitions and indicators. After the definitions and indicators are obtained, then arranged instruments that are able to bring up the mathematical imagination in accordance with the definitions and indicators obtained to be tested for legibility and validity. The instrument is then arranged into a test instrument in the form of a description. The test instrument is then tested for readability. After the readability test, which instruments were selected by students and which were not, besides revisions were also made if there were comments from students. The instrument that has been declared good in its readability test is then tested for validity by experts. The instrument was revised again based on advice from experts on the validity test that had been carried out.

Data analysis conducted in this study was data reduction, data presentation, and drawing conclusions or data verification. Data reduction is done by sorting the data obtained from the readability test and the validity test. Based on the data obtained, the data is presented in tabular and description form. Presentation of data is done to be able to see the whole part of the data. Presentation of data is done to facilitate conclusions.

\section{Result and Discussion}

\subsection{Result}

The sequence of mathematical can see in Figure 1.

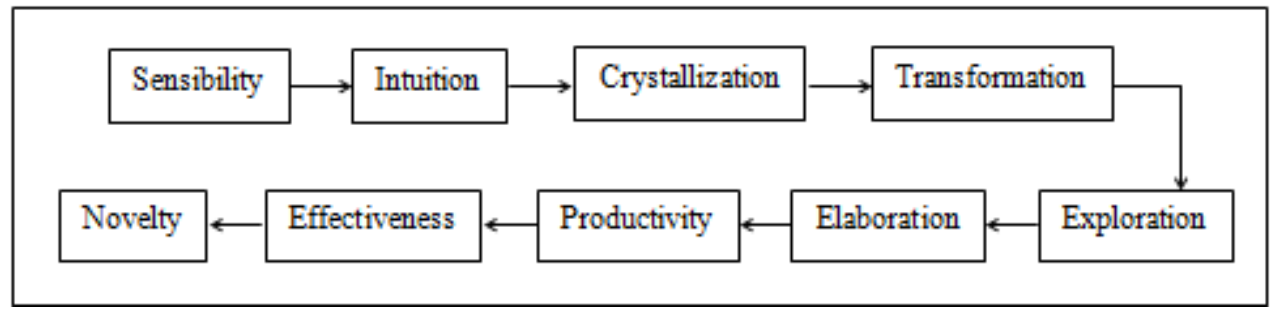

Figure 1. Sequence Indicator of mathematical imagination 
Second, prepare an instrument based on indicators of mathematical imagination. The steps at this stage include preparation of items, preparation of preparation of draft instruments, and preparation of validation sheets. Complications of questions are based on the results of the analysis of the 2013 curriculum mathematics syllabus. The initial draft of the test instrument in the form of a description arranged as many as 12 items. Validation sheets that are compiled are used to find out whether the validated instrument can be used correctly. The number of statements in the validation sheet is 9 statements covering aspects of construction, language, and material.

Third, test the validity and legibility of the instruments prepared. Data collection was carried out using a questionnaire. This questionnaire is used to test readability and validity. The questionnaire for the legibility test was given to 30 students, as research subjects. The following is a summary of the readability test results in table 1 :

Table 1. Summary of Readability Test Results

\begin{tabular}{|c|c|c|c|c|c|c|c|c|c|c|c|c|}
\hline \multirow{2}{*}{ Subject } & \multicolumn{12}{|c|}{ Question Item } \\
\hline & 1 & 2 & 3 & 4 & 5 & 6 & 7 & 8 & 9 & 10 & 11 & 12 \\
\hline $1^{\text {st }}$-Subject & $\sqrt{ }$ & $\sqrt{ }$ & $\sqrt{ }$ & $\sqrt{ }$ & - & $\sqrt{ }$ & $\sqrt{ }$ & $\sqrt{ }$ & $\sqrt{ }$ & $\sqrt{ }$ & - & - \\
\hline $2^{\text {nd }}-$ Subject & $\sqrt{ }$ & $\sqrt{ }$ & $\sqrt{ }$ & $\sqrt{ }$ & $\sqrt{ }$ & $\sqrt{ }$ & $\sqrt{ }$ & $\sqrt{ }$ & $\sqrt{ }$ & - & $\sqrt{ }$ & $\sqrt{ }$ \\
\hline $3^{\text {rd }}$-Subject & $\sqrt{ }$ & $\sqrt{ }$ & $\sqrt{ }$ & $\sqrt{ }$ & $\sqrt{ }$ & $\sqrt{ }$ & $\sqrt{ }$ & $\sqrt{ }$ & $\sqrt{ }$ & $\sqrt{ }$ & - & $\sqrt{ }$ \\
\hline $4^{\text {th }}$-Subject & $\sqrt{ }$ & $\sqrt{ }$ & $\sqrt{ }$ & $\sqrt{ }$ & $\sqrt{ }$ & $\sqrt{ }$ & $\sqrt{ }$ & $\sqrt{ }$ & - & - & $\sqrt{ }$ & $\sqrt{ }$ \\
\hline $5^{\text {th }}$-Subject & $\sqrt{ }$ & $\sqrt{ }$ & $\sqrt{ }$ & $\sqrt{ }$ & $\sqrt{ }$ & $\sqrt{ }$ & $\sqrt{ }$ & $\sqrt{ }$ & - & - & $\sqrt{ }$ & - \\
\hline $6^{\text {th }}$-Subject & $\sqrt{ }$ & $\sqrt{ }$ & $\sqrt{ }$ & $\sqrt{ }$ & $\sqrt{ }$ & $\sqrt{ }$ & - & $\sqrt{ }$ & $\sqrt{ }$ & - & - & - \\
\hline $7^{\text {th }}$-Subject & $\sqrt{ }$ & $\sqrt{ }$ & $\sqrt{ }$ & $\sqrt{ }$ & $\sqrt{ }$ & $\sqrt{ }$ & $\sqrt{ }$ & $\sqrt{ }$ & $\sqrt{ }$ & - & $\sqrt{ }$ & $\sqrt{ }$ \\
\hline $8^{\text {th }}$-Subject & $\sqrt{ }$ & $\sqrt{ }$ & $\sqrt{ }$ & $\sqrt{ }$ & $\sqrt{ }$ & $\sqrt{ }$ & $\sqrt{ }$ & $\sqrt{ }$ & $\sqrt{ }$ & - & $\sqrt{ }$ & $\sqrt{ }$ \\
\hline $9^{\text {th }}$-Subject & $\sqrt{ }$ & $\sqrt{ }$ & $\sqrt{ }$ & $\sqrt{ }$ & $\sqrt{ }$ & $\sqrt{ }$ & $\sqrt{ }$ & $\sqrt{ }$ & $\sqrt{ }$ & $\sqrt{ }$ & $\sqrt{ }$ & $\sqrt{ }$ \\
\hline $10^{\text {th }}$-Subject & $\sqrt{ }$ & $\sqrt{ }$ & $\sqrt{ }$ & $\sqrt{ }$ & - & $\sqrt{ }$ & - & $\sqrt{ }$ & - & - & - & - \\
\hline $11^{\text {th }}$-Subject & $\sqrt{ }$ & $\sqrt{ }$ & $\sqrt{ }$ & $\sqrt{ }$ & $\sqrt{ }$ & $\sqrt{ }$ & $\sqrt{ }$ & $\sqrt{ }$ & $\sqrt{ }$ & $\sqrt{ }$ & $\sqrt{ }$ & $\sqrt{ }$ \\
\hline $12^{\text {th }}$-Subject & $\sqrt{ }$ & $\sqrt{ }$ & $\sqrt{ }$ & $\sqrt{ }$ & $\sqrt{ }$ & $\sqrt{ }$ & - & $\sqrt{ }$ & - & $\sqrt{ }$ & $\sqrt{ }$ & - \\
\hline $13^{\text {th }}$-Subject & $\sqrt{ }$ & $\sqrt{ }$ & $\sqrt{ }$ & $\sqrt{ }$ & $\sqrt{ }$ & $\sqrt{ }$ & - & $\sqrt{ }$ & $\sqrt{ }$ & $\sqrt{ }$ & - & $\sqrt{ }$ \\
\hline $14^{\text {th }}$-Subject & $\sqrt{ }$ & $\sqrt{ }$ & $\sqrt{ }$ & $\sqrt{ }$ & $\sqrt{ }$ & $\sqrt{ }$ & $\sqrt{ }$ & $\sqrt{ }$ & $\sqrt{ }$ & - & - & - \\
\hline $15^{\text {th }}$-Subject & $\sqrt{ }$ & $\sqrt{ }$ & $\sqrt{ }$ & $\sqrt{ }$ & - & $\sqrt{ }$ & $\sqrt{ }$ & $\sqrt{ }$ & $\sqrt{ }$ & - & $\sqrt{ }$ & $\sqrt{ }$ \\
\hline $16^{\text {th }}$-Subject & $\sqrt{ }$ & $\sqrt{ }$ & $\sqrt{ }$ & $\sqrt{ }$ & - & $\sqrt{ }$ & $\sqrt{ }$ & $\sqrt{ }$ & - & - & $\sqrt{ }$ & $\sqrt{ }$ \\
\hline $17^{\text {th }}$-Subject & $\sqrt{ }$ & $\sqrt{ }$ & $\sqrt{ }$ & $\sqrt{ }$ & $\sqrt{ }$ & $\sqrt{ }$ & $\sqrt{ }$ & $\sqrt{ }$ & - & $\sqrt{ }$ & $\sqrt{ }$ & $\sqrt{ }$ \\
\hline $18^{\text {th }}$-Subject & $\sqrt{ }$ & $\sqrt{ }$ & $\sqrt{ }$ & $\sqrt{ }$ & $\sqrt{ }$ & $\sqrt{ }$ & - & $\sqrt{ }$ & $\sqrt{ }$ & $\sqrt{ }$ & $\sqrt{ }$ & - \\
\hline $19^{\text {th }}$-Subject & $\sqrt{ }$ & $\sqrt{ }$ & $\sqrt{ }$ & $\sqrt{ }$ & $\sqrt{ }$ & $\sqrt{ }$ & $\sqrt{ }$ & $\sqrt{ }$ & $\sqrt{ }$ & $\sqrt{ }$ & - & $\sqrt{ }$ \\
\hline $20^{\text {th }}$-Subject & $\sqrt{ }$ & $\sqrt{ }$ & $\sqrt{ }$ & $\sqrt{ }$ & - & $\sqrt{ }$ & - & $\sqrt{ }$ & - & $\sqrt{ }$ & - & $\sqrt{ }$ \\
\hline $21^{\text {st }}$-Subject & $\sqrt{ }$ & $\sqrt{ }$ & $\sqrt{ }$ & $\sqrt{ }$ & $\sqrt{ }$ & $\sqrt{ }$ & $\sqrt{ }$ & $\sqrt{ }$ & $\sqrt{ }$ & $\sqrt{ }$ & $\sqrt{ }$ & $\sqrt{ }$ \\
\hline $22^{\text {nd }}-$ Subject & $\sqrt{ }$ & $\sqrt{ }$ & $\sqrt{ }$ & $\sqrt{ }$ & $\sqrt{ }$ & $\sqrt{ }$ & $\sqrt{ }$ & $\sqrt{ }$ & $\sqrt{ }$ & - & $\sqrt{ }$ & $\sqrt{ }$ \\
\hline $23^{\text {rd }}$-Subject & $\sqrt{ }$ & $\sqrt{ }$ & $\sqrt{ }$ & $\sqrt{ }$ & $\sqrt{ }$ & $\sqrt{ }$ & - & $\sqrt{ }$ & $\sqrt{ }$ & $\sqrt{ }$ & - & - \\
\hline $24^{\text {th }}$-Subject & $\sqrt{ }$ & $\sqrt{ }$ & $\sqrt{ }$ & $\sqrt{ }$ & - & $\sqrt{ }$ & $\sqrt{ }$ & $\sqrt{ }$ & - & $\sqrt{ }$ & - & - \\
\hline $25^{\text {th }}$-Subject & $\sqrt{ }$ & $\sqrt{ }$ & $\sqrt{ }$ & $\sqrt{ }$ & $\sqrt{ }$ & $\sqrt{ }$ & $\sqrt{ }$ & $\sqrt{ }$ & - & - & $\sqrt{ }$ & - \\
\hline $26^{\text {th }}$-Subject & $\sqrt{ }$ & $\sqrt{ }$ & $\sqrt{ }$ & $\sqrt{ }$ & $\sqrt{ }$ & $\sqrt{ }$ & - & $\sqrt{ }$ & $\sqrt{ }$ & - & $\sqrt{ }$ & - \\
\hline $27^{\text {th }}$-Subject & $\sqrt{ }$ & $\sqrt{ }$ & $\sqrt{ }$ & $\sqrt{ }$ & $\sqrt{ }$ & $\sqrt{ }$ & $\sqrt{ }$ & $\sqrt{ }$ & $\sqrt{ }$ & $\sqrt{ }$ & - & $\sqrt{ }$ \\
\hline $28^{\text {th }}$-Subject & $\sqrt{ }$ & $\sqrt{ }$ & $\sqrt{ }$ & $\sqrt{ }$ & - & $\sqrt{ }$ & $\sqrt{ }$ & $\sqrt{ }$ & - & $\sqrt{ }$ & - & - \\
\hline $29^{\text {th }}$-Subject & $\sqrt{ }$ & $\sqrt{ }$ & $\sqrt{ }$ & $\sqrt{ }$ & $\sqrt{ }$ & $\sqrt{ }$ & $\sqrt{ }$ & $\sqrt{ }$ & $\sqrt{ }$ & - & - & $\sqrt{ }$ \\
\hline $30^{\text {th }}$-Subject & $\sqrt{ }$ & $\sqrt{ }$ & $\sqrt{ }$ & $\sqrt{ }$ & - & $\sqrt{ }$ & $\sqrt{ }$ & $\sqrt{ }$ & $\sqrt{ }$ & - & $\sqrt{ }$ & - \\
\hline Decision & good & good & good & good & bad & good & bad & good & bad & bad & bad & bad \\
\hline
\end{tabular}

Notes: $\sqrt{ } \quad=$ can be understood by students

- $\quad=$ cannot be understood by students 
Based on Table 1 it is known that questions number 1, 2, $3,4,6$, and 8 can be understood by all students. Problem number 5 and 7 , there are 8 students who don't understand the problem. Meanwhile, with question number 9 , there are 10 students who do not understand this problem. Questions number 11 and 12 cannot be understood by 13 students. and finally, question number 10 cannot be understood by 15 students. Thus, there are 6 questions that can be fully understood by 30 students, while the other 6 questions cannot be understood by some students. thus, 6 questions that can be understood can be used as research instruments, while 6 other questions cannot be used. Students cannot understand because they judge editorial writing from complex questions which are difficult to solve.

The results of the validity test were conducted by 2 teachers, namely the selection of items that were in accordance with the school curriculum and that were not in accordance with the school curriculum, especially the curriculum for 8th grade junior high school students. Validity test conducted by 2 learning evaluation tool experts, 1 mathematics education lecturer and 1 mathematics instructor stated that the questions compiled had fulfilled all the test indicators given. The indicators in question are examined in several aspects, namely in terms of construction, grammar, and material aspects.

In terms of construction related to: (1) whether the question has the potential to produce students' mathematical imagination, (2) whether the question is formulated briefly and clearly, (3) whether the question does not depend on the answers to other items, and (4) whether the information given in the problem is enough to solve the problem. Language requirements are related to: (1) whether the question is free from statements that can lead to several interpretations, (2) whether the question uses good and correct Indonesian language rules, and (3) whether the question uses words or terms that students know.

Material provisions relate to: (1) whether the question material has been studied by students, (2) whether the answer key for each item is correct, and (3) whether the question is not too easy and not too difficult. However, there are suggestions from validators to make related revisions. The revision in the question is the simplification of the sentence so that it is better understood by students, correcting the answer key to be more detailed, and ordering a number of questions starting from the question that is considered the easiest first to the most difficult question.

\subsection{Discussion}

The first step taken in compiling an instrument of mathematical imagination ability is to study literature and examine examples of existing mathematical imagination instruments. This is done so that the instrument produced is right, because it has been holding on to existing concepts and theories. This step is in line with research that has been done, where during the development of the instrument, a collection of question items was made by scanning relevant literature and examining other similar instruments [16].

In the literature study and examination of mathematical imagination instruments before, the points prepared were indicators of mathematical imagination ability consisting of sensibility, intuition, crystallization, transformation, exploration, elaboration, productivity, effectiveness, and novelty [15]. Based on these indicators of mathematical imagination, the items are arranged in order to be able to see, describe and measure the ability of mathematical imagination possessed by students. This is in accordance with the results of research that has been done, where the points of the instruments prepared, are related to the research objectives to be achieved. In this study the instrument developed can also be used to measure teaching capacity [17].

After the instrument is arranged, then the instrument is tested for legibility and validity. Readability test is carried out for whether the instruments arranged have a good category in terms of readability or not. Instruments that have a good category are instruments that can be easily understood by students. The readability test results show that 6 items in the good category and 6 other item items in the poor category. Meanwhile, the validity test is carried out to find out whether the instruments that are arranged are correct or not. This means that the instrument can give an idea of the mathematical imagination ability possessed by junior high school students. The validation results state that 3 items are valid without revision, 3 items need to be revised, 1 item needs to be revised answer key. The validator also recommends ordering problems from easy to more difficult questions. So 6 questions can be used even though 3 questions have a slight revision. Meanwhile, 6 other questions were declared invalid. Based on the results of the readability and validity tests conducted, 6 items of mathematical imagination instruments can be used.

The instrument was examined by experts in the fields according to the expected assessment aspects, namely mathematics learning experts, learning evaluations, and education sciences. Mathematics learning experts, test the suitability of instruments made between the content of the material compiled and the content of material that has been studied in mathematics learning at school. Learning evaluation experts, test the suitability of the structure of the instrument made with the rules of an appropriate learning evaluation instrument. Meanwhile, education experts, test the suitability of the instruments compiled with the rules of psychological development of junior high school students. This was also done in previous studies, where the prepared instrument material was rechecked according to the opinions of lecturers working in the Turkish language education and in the science of education [16].

Validity test results were obtained from validation sheets given to experts when examining the instrument [18]. The instruments that have been examined by experts are then 
described and used as an improvement material to get the right instruments. This is different from other studies that have been conducted, where the results of examinations by experts are then calculated using Aiken. That is, the validity test is carried out qualitatively and quantitatively [19]. Instruments that have been declared valid, can provide evidence of high reliability [20].

The implication of the results of this study is to obtain a test instrument in the form of a description to get a picture of students' mathematical imagination processes. The recommendation given is that further research should be done by validating indicators of mathematical imagination so that more varied items are obtained. in addition, tests conducted on the instrument are not only readability and validity tests.

\section{Conclusions}

The conclusions in this study are: 1) The stages of the validation of the test instrument consist of a) the preparation of the test instrument by conducting a library study to get a definition and indicator of students' mathematical imagination abilities; b) test the instrument in the form of readability test and validity test; 2) Readability test results state that of the 12 items created there are 6 questions that can be used and there are 6 questions that cannot be used; 3 ) The validity test results state that there are 3 valid items without revisions, 3 valid items with few revisions, and 1 item needs to be revised answer key. in addition, questions need to be sorted from the easiest questions to the most difficult questions.

This research has several limitations in the process. To be able to improve the results of further research, it is necessary to improve a number of things. In this study, there were only 12 items tested. This causes the input obtained in making a valid instrument is not much. In addition, the number of experts who tested the validity of the instrument only came from 3 fields, namely mathematics learning, evaluation of learning, education. Henceforth it is necessary to involve experts in the language and psychology fields. Experts in the language field will help provide an instrument assessment in terms of grammar. Experts in the field of psychology will help provide input on item items that can give rise to the imagination. In this study, the instrument in the form of a questionnaire only contained yes / no choices. For future research it is better to use a Likert scale so that in addition to being described qualitatively it can also be described quantitatively.

\section{REFERENCES}

[1] Gelişli, Y. \& Beisenbayeva, L.: Scientific Inquiry
Competency Perception Scale (The Case of Kazak Post-Graduate Students) Reliability and Validity Study. International Journal of Instruction, 10 (1), pp. 273-288 (2017)

[2] Purnomo, Y. W.: A Scale for Measuring Teachers' Mathematics-Related Beliefs: A Validity and Realiability Study. International Journal of Instruction, 10 (2), pp. 23-38 (2017)

[3] Nordin, H., Faekah, T., \& Ariffin, T.: Validation of A Technological Pedagogical Content Knowledge Instrument In A Malaysian Secondary School Context. Malaysian Journal of Learning and Instruction, 13, pp. 1-24 (2016)

[4] Thaneerananon, T., Triampo, W., \& Nokkaew, A.: Development of a Test to Evaluate Students' Analytical Thinking Based on Fact Versus Opinion Differentiation. International Journal of Instruction, 9 (2), pp. 123-138 (2016)

[5] Hengpiya, A.: Construct Validation of a School Principal Decision-Making Styles Scale. Malaysian Journal of Learning and Instruction, 5, pp. 41-61 (2008)

[6] Purwanto. Metodologi Penelitian Kuantitatif. Yogyakarta: Pustaka Pelajar (2010)

[7] Colton, David \& Robert W.: Designing and Constructing Instruments for Social Research and Evaluation. San Francisco: Jossey-Basse (2007)

[8] Kothari, C. R.: Research Methodology, New Delhi: New Age International Publisher (2004)

[9] Damsa, C., \& Jornet, A.: Revisiting learning in higher education-Framing notions redefined through an ecological perspective. Frontline Learning Research, 4 (4), pp. 39-47. (2016)

[10] Nemirovsky, R., Rasmussen, C., Sweeney, G., \& Wawro, M.: When the classroom floor becomes the complex plane: Addition and multiplication as ways of bodily navigation. Journal of the Learning Sciences, 21(2), pp. 287-323 (2012)

[11] Pelaprat, E., \& Cole, M.: "Minding the Gap”: Imagination, Creativity and Human Cognition. Integrative Psychological and Behavioral Science, 45(4), pp. 397-418 (2011)

[12] Heath, G.: Exploring the imagination to establish frameworks for learning. Study Philosophy of Education, 27(2), pp. 115-123 (2008)

[13] Hsu, Y.: The Comparison of Mediating Models for Stimulating Imagination with Psychological and Environmental Factors, 12 (3), pp. 13-27 (2015)

[14] Liang, C. \& Lin, W. S.: The Interplay ofCreativity, Imagination,Personality Traits, andAcademic Performance. Imagination, Cognition andPersonality: Consciousness inTheory, Research, and ClinicalPractice, 34(3), pp. 270-290 (2015).

[15] Nurcahyono, N. A. Suryadi, D. Prabawanto, S. \& Novarina, E.: Sequence indicators of Junior High School Students“ Mathematical Imagination Abilities. International Journal of Education, Information, and Technology and Others, 3(1), pp. 75-86 (2020).

[16] Varışoğlu, B.: Turkish Metalinguistic Awareness Scale: A Validity and Reliability Study. Universal Journal of 
Educational Research, 6(4), pp. 691-700(2018).

[17] Yalçın, M. T. \& Ereş, F.:A Study of Validity and Reliability on theInstructional Capacity Scale. Universal Journal of Educational Research, 6(1): 57-67 (2018).

[18] Budiwan, J. Hidayatullah, F. Yusuf, M. \&Asrowi.: Validity Test of the Family Supported CollaborativeLearning (FSCL) Model to Instill Character Values toJunior High School Students.Universal Journal of Educational Research, 8(3D), pp. 1-6 (2020).

[19] Sumantri. Kumaidi. \&Herawati, L.: The Assessment of Continuous Antenatal CareCompetence in Midwifery Diploma Education:Instrument Development and Content Validation. Universal Journal of Educational Research, 7(11), pp. 2287-2292 (2019).

[20] Bulut, B. \&Karasakaloğlu, N.: Digital Reading Disposition Scale: A Study ofValidity and Reliability.Universal Journal of Educational Research, 6(4), pp. 613-618 (2018). 